\title{
Hunting Bambi-evaluating the basis for selective harvesting of juveniles
}

\author{
Jos M. Milner • Christophe Bonenfant • Atle Mysterud
}

Received: 11 June 2010 /Revised: 19 October 2010 /Accepted: 25 October 2010 /Published online: 19 November 2010

(C) The Author(s) 2010. This article is published with open access at Springerlink.com

\begin{abstract}
Human harvesting is often a major mortality factor and, hence, an important proximate factor driving the population dynamics of large mammals. Several selective harvesting regimes focus on removing animals with low reproductive value, such as "antlered" harvests in North America and juvenile harvesting in many European countries. Despite its widespread use and assumed impact, the scientific basis of juvenile harvesting is scattered in the literature and not empirically well-documented. We give the first overview of demographic, evolutionary and practical management arguments for selective harvesting of juveniles. Furthermore, we empirically test two demographic arguments based on harvest statistics of Red Deer (Cervus elaphus) in seven European countries. $\mathrm{P}_{1}$ : Harvesting juveniles has little influence on harvest growth compared with harvesting adult females due to the lower reproductive value of juveniles than adult females; $\mathrm{P}_{2}$ : Harvesting of
\end{abstract}

Communicated by C. Gortázar

J. M. Milner $(\bowtie)$

Department of Forestry and Wildlife Management,

Hedmark University College,

Evenstad,

NO-2480, Koppang, Norway

e-mail: jos.milner@hihm.no

C. Bonenfant

UMR CNRS 5558, Laboratoire Biométrie et Biologie Évolutive,

Université Claude Bernard Lyon 1,

43, Bvd du 11 Novembre 1918,

69622, Villeurbanne Cedex, France

\section{A. Mysterud}

Centre for Ecological and Evolutionary Synthesis (CEES),

Department of Biology, University of Oslo,

P.O. Box 1066 Blindern,

NO-0316, Oslo, Norway juveniles dampens variance in harvest due to lower and more variable natural survival rates of juveniles compared with adults. We found that harvesting juveniles has little effect on harvest growth rate, while harvesting adult females has a significant negative effect (consistent with $\mathrm{P}_{1}$ ), but that increasing the proportion of juveniles in the harvest did not decrease the variability in harvest between years $\left(\mathrm{P}_{2}\right.$ not supported). Based on our empirical findings and overview of arguments, we discuss how the merits of juvenile harvesting may vary over time as populations move from a low density to a very high density state.

Keywords Deer management - Exploitation · Population dynamics - Ungulates · Sustainable management . Wildlife cropping

\section{Introduction}

Populations of large herbivores have been expanding in range and increasing in density across Europe and North America in recent decades (Côté et al. 2004; Gordon et al. 2004; Milner et al. 2006). Several factors have contributed to this increase, including increased availability of forage resulting from changes in land use (Ahlén 1975), agriculture and forestry practices (Mysterud et al. 2002b), a functional absence of large carnivores and climatic changes resulting in milder winters (Mysterud et al. 2003). However, changes in cervid management, particularly regarding selective harvesting regimes (Langvatn and Loison 1999; Østgård 1987; Solberg et al. 1999), have also occurred during the same time period and are probably one of the most important proximate causes of the observed increases in abundance, at least in areas where human harvesting is a major mortality factor. 
The principles of sustainable exploitation are based on life history theory, an understanding of population dynamics and the assumption of density dependence (Sutherland 2001; McCullough 1996). Selective harvesting focuses the offtake on predetermined sex-, size- and/or age-classes which vary depending on management objectives (Caughley 1977; Fenberg and Roy 2008). For example, in North America, large game harvesting was often managed as an 'antlered hunt'. This protected adult females during a period of population recovery following commercial over-exploitation in the nineteenth century. However, today, it results in suboptimal yields (McCullough 2001) and over-abundance problems (McShea et al. 1997) such that non-antlered hunts are often also necessary. By contrast, in Scandinavia, population productivity and yield of game animals, particularly moose (Alces alces), have increased enormously since the 1970s when a policy of heavily harvesting juveniles and adult males was adopted (Østgård 1987; Solberg et al. 1999). Prior to this, it was illegal to shoot juveniles in Scandinavia and other parts of Western Europe, although, in central Europe, there has been a long tradition of hunting juveniles. In Austria, for example, the Reichsjagdgesetz hunting law, introduced in the $1930 \mathrm{~s}$, specified culling $1 / 3$ males, $1 / 3$ females and 1/3 calves (Mitschke 1960) in order to maintain stable populations.

Hunters are often reluctant to shoot juveniles (Østgård 1987; Sæther et al. 2009; Festa-Bianchet 2007) and frequently ask managers why they should do so. There are a number of reasons, scattered in the literature. We provide the first overview and classification of these into demographic, evolutionary and practical management arguments (reviewed in Table 1). The origins of these arguments are not always clear and are very often unsupported statements, verbal arguments or theoretical ideas with little empirical backing. Today, it is not even always clear whether these arguments are still valid, given the increasing occurrence of over-abundant ungulate populations in the developed world.

Demographic theory indicates that, in certain circumstances, there should be two very strong arguments for selectively harvesting juveniles rather than adults (Table 1). Firstly, that population productivity will be enhanced, as observed in the Scandinavian moose and Red Deer (Cervus elaphus) and secondly that population size and, hence, annual hunting bags will be less variable. Since reproductive value in most ungulates increases to a peak around the age of first reproduction and then declines (Stearns 1992), juveniles have a low reproductive value compared with yearling and adult females (Sæther et al. 2007). Selective harvesting of individuals with low reproductive value (juveniles and adult males) should have a relatively low impact on future population growth compared with harvesting the same number of adult females (Ericsson et al.
2000). By sparing adult females, the average age and, hence, reproductive output of a population can be increased (Solberg et al. 1999). Simulation models of moose show that such a harvesting strategy can increase harvest yield (Haagenrud and Lørdahl 1974; Sæther et al. 1992, 2001) and population growth rate (Ericsson et al. 2000), while reducing variance in the harvest (Sæther et al. 1992).

Among large herbivores, including many important game species, population growth is generally more sensitive to variation in adult survival than juvenile survival (Gaillard et al. 2000). However, in the absence of harvesting, adult survival tends to be high and fairly constant from year to year compared with the highly variable recruitment of juveniles (Gaillard et al. 1998). This temporal variability in juvenile recruitment means that it may nonetheless have a greater importance in determining population changes than adult survival (Gaillard et al. 2000, 2003). The proportion of a population consisting of juveniles could therefore have important consequences for population stability or, conversely, vulnerability to stochastic environmental events. Sport hunting, as currently practised, tends to focus on adult individuals (Milner et al. 2006) with the result that many harvested populations have greater proportions of juveniles than unexploited populations (Ginsberg and Milner-Gulland 1994; Festa-Bianchet 2007). Consequently, Gordon et al. (2004) predicted that growth rates of such populations are likely to vary more in response to density and harsh weather conditions than unharvested or lightly harvested populations.

There have, however, been few empirical tests of the expected effects of harvesting juveniles on the population dynamics or harvest yield (Table 1). Here, we use harvest data to assess the extent to which theoretical expectations and modelling predictions are met. We use data from Red Deer hunting bags, over 24-42 years, in seven European countries with contrasting harvesting policies, to investigate the effect of harvesting juveniles on harvest growth and variability. Specifically, we test two predictions at national and regional spatial scales: (1) harvesting calves has little influence on harvest growth compared with harvesting adult females because of the low reproductive value of juveniles, and (2) the greater the representation of calves in the total harvest, the lower the year-to-year variability in harvest size because of the greater sensitivity of juveniles to random environmental conditions.

\section{Materials and methods}

Annual size and composition of harvests

Annual size and composition of national Red Deer harvests were obtained for the period 1965-2006 for Austria, France 


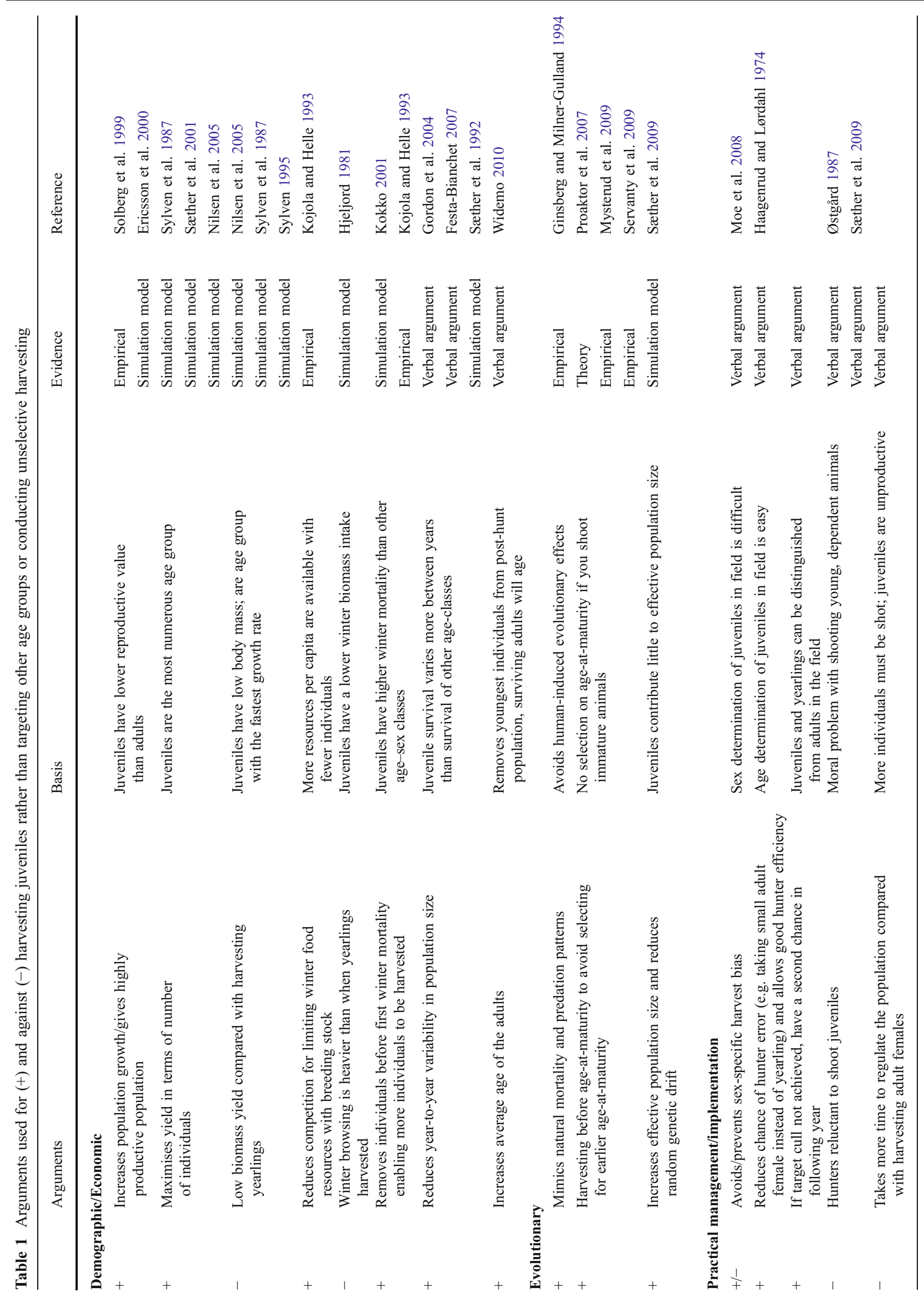


(from 1983), Hungary (from 1969), Norway (full composition data from 1977), Scotland, Slovenia and Switzerland from national bodies in the respective countries (see Milner et al. 2006 for further details). Reliable data describing population size and structure were largely unavailable at this spatial scale and, hence, harvest rates were unknown. Regional harvest data were also used, taken from the region with the largest Red Deer harvest in each of four focal countries with differing management systems: France (Bas-Rhin), Hungary (Somogy), Norway (Sogn and Fjordane) and Scotland (Cairngorm and West Grampian). The year of harvest was taken from the start of the hunting season in autumn. Harvest composition was classified in terms of the number of calves, adult males ( $\geq 1$ year) and adult females ( $\geq 1$ year) shot. The proportion of calves in the harvest increased throughout the study period in all countries, while the sex ratio of the adult harvest remained relatively constant (Milner et al. 2006).

\section{Analysis}

We first investigated harvest composition at the country level with a centred principal component analysis (PCA; Legendre and Legendre 1998) using proportions of males, females and calves harvested each year in each country as principal component loadings implemented in the 'ade4' package of R (Dray and Dufour 2007). A scatter-plot of the normed PCA scores grouped by country showed similarities and differences between countries according to their harvest composition.

Harvest composition was constrained to sum up to one for each country or region, so we took a compositional analysis approach (Aitchison 1986) and used log ratio transformations of the number of calves and adult females, each in relation to the number of adult males. The transformed number of calves was, nonetheless, positively correlated with the transformed number of adult females (national harvests $r=0.250, p<0.001$; regional harvests $r=0.443, p<0.001)$. Harvest growth rate $(\mathrm{Hr})$ was calculated for each country or region as the annual change in harvest size: $\log _{n}\left(h_{t+1}\right)-\log _{n}\left(h_{t}\right)$ where $h_{t}$ is the size of the total harvest in year $t$ (Caughley 1977). We assume harvest growth rates mimic population growth rates over the longer term and found no evidence of a density-dependent decline at either spatial scale (Milner et al. 2006).

To test prediction 1 , we investigated the influence of harvest composition in year $t$ on $H r$ in year $t$ (i.e. the change in harvest size between year $t$ and $t+1$ ) and $t+1$ (the change between year $t+1$ and $t+2$ ) in case of a time lag between the harvest and its effect on harvest growth. We used generalised least squares (GLS) models (Pinheiro and Bates 2000) for the national harvest data and simple linear models for the regional harvests. GLS models allowed both the mean and variance of the response variable to be modelled and accounted for heteroscedasticity between countries (Pinheiro and Bates 2000; Zuur et al. 2009). The amount of variation explained by GLS models was assessed by a generalised $R^{2}$, calculated as the square of the correlation between the observed and fitted values (Zheng and Agresti 2000).

To test prediction 2, concerning the relationship between calf harvesting and variability in harvest size, we first detrended harvest size and the proportion of calves in the harvest to take account of the considerable increase over time in both parameters throughout the study period (Grosbois et al. 2008). We took the residuals of a linear model of $\log _{n}$ harvest size in year $t+1$ against year, fitted as a second order polynomial, and its interaction with country or region. We detrended the proportion of calves in the harvest in the same way. We then modelled the variance in detrended harvest size by fitting GLS models with detrended proportion of calves and its interactions with year and country or region as fixed effects. All analyses were carried out using R 2.5.1 (R Development Core Team 2007).

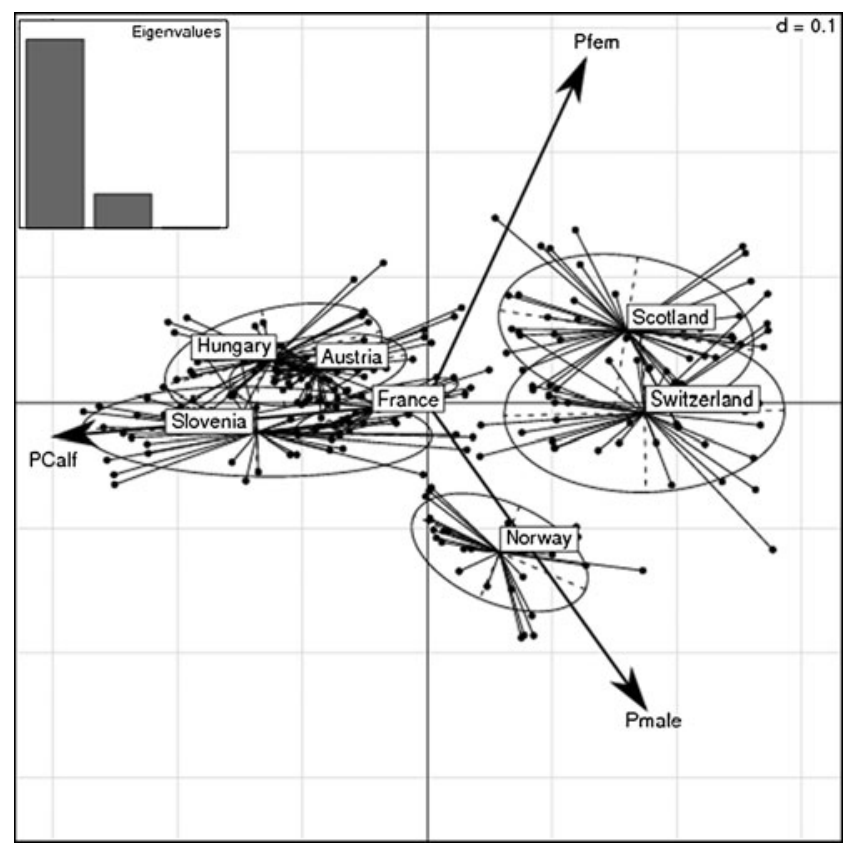

Fig. 1 Differences in Red Deer harvest composition between countries, as revealed by principle component analysis. The proportion of calves in the harvest increases from right to left, while the adult harvest shifts from being female-biased at the top to male biased at the bottom. The size of the ellipses indicates the amount of between-year variability. The length of the arrow shows the strength of the correlation between the different observed variables (proportion of calves, females and males in the harvest) and the principal components. The Eigen values histogram measures the relative amount of variability explained by each principal component 


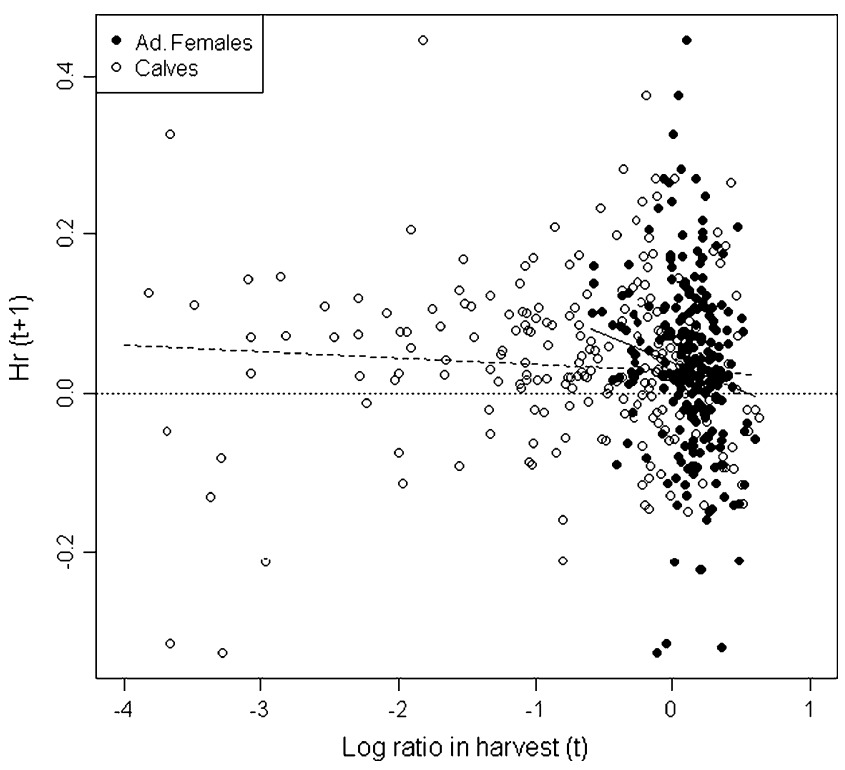

Fig. 2 The influence of harvest composition in year $t$, in terms of the log ratio transformed number of calves and adult females in the harvest, on harvest growth rate $(\mathrm{Hr})$ in year $t+1$ at the national level. The fitted GLS models, which accounted for differences in variance between countries, were $H r_{t+1}=0.038-0.069 *$ females $_{t}$ (solid line) for adult females and $\mathrm{Hr}_{t+1}=0.028-0.008 * \mathrm{calves}_{t}$ (dashed line) for calves

\section{Results}

European picture of harvest composition

The first two PCA principal components accounted for $84.3 \%$ and $15.3 \%$ of the total inertia, respectively. The first and most discriminating component separated countries in terms of the proportion of juveniles versus adults in the harvest while the second component separated countries by the adult sex ratio. Figure 1 shows that France and central European countries took relatively large calf harvests compared with Scotland and Switzerland, while Norway took a strongly male-biased adult harvest compared with other countries.

The effect of harvest composition on harvest growth

At the national level, the number of adult females in the harvest had a small but significant negative influence on harvest growth rate $(\mathrm{Hr})$ in year $t(-0.074 ; 95 \%$ confidence intervals $(\mathrm{CI})-0.116,-0.032$; generalised $\left.R^{2}=0.025\right)$ and year $t+1\left(-0.069 ; 95 \%\right.$ CI $-0.109,-0.029$; generalised $R^{2}$ $=0.032$; Fig. 2). At the regional level, the number of adult females in the harvest had a significant negative effect on lagged $\mathrm{Hr}$ in Hungary and Norway (Hungary ${ }_{t+1}-0.290$; $95 \%$ CI $-0.510,-0.070 ;$ Norway $_{t+1}-0.226 ; 95 \%$ CI $-0.413,-0.039$; Fig. 3) while in the French region of Bas-Rhin harvest composition had no effect on $\mathrm{Hr}$ in either year $t$ or $t+1$ and in the Scottish region of Cairngorm
Fig. 3 The influence of harvest composition in year $t$, in terms of the log ratio transformed number of calves (open points) and adult females (filled points) in the harvest, on harvest growth rate $(H r)$ in year $t+1$ in regional harvests of four countries.

Fitted lines are regression lines (dotted lines: calves, solid lines: adult females)
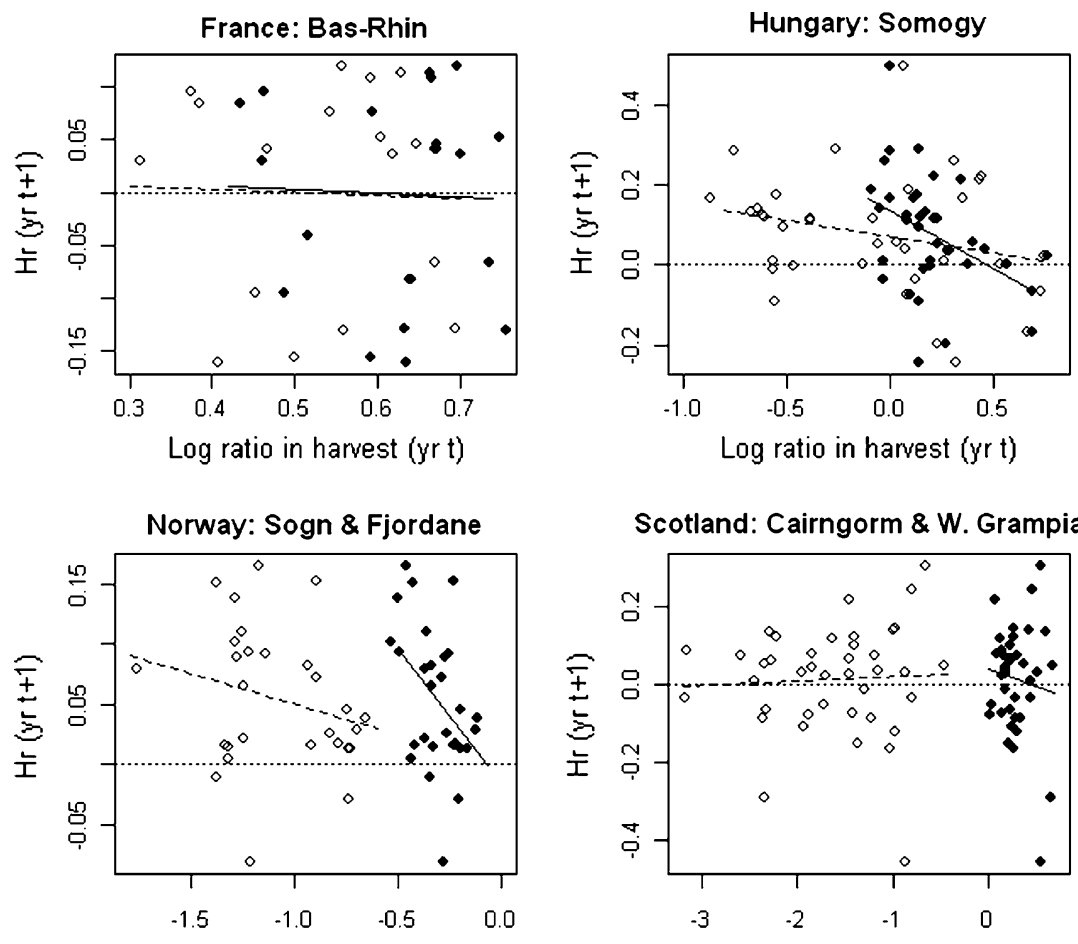

Log ratio in harvest (yr t)

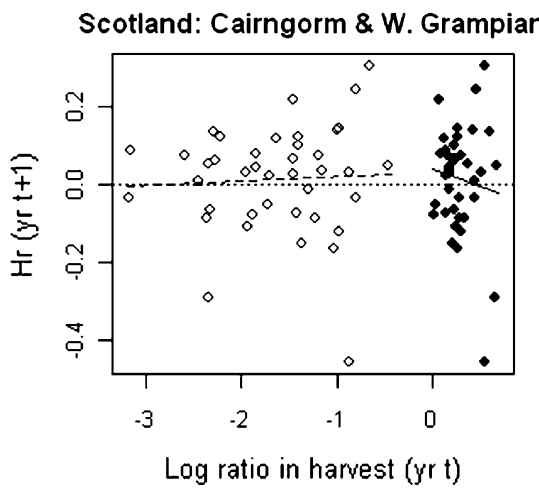




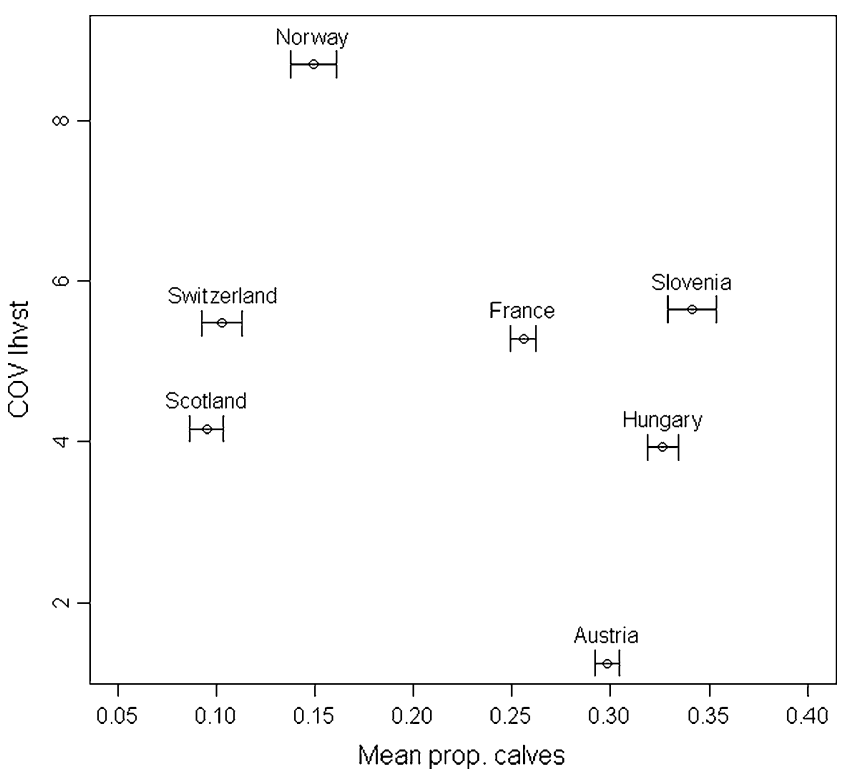

Fig. 4 Coefficient of variation of $\log _{n}$ harvest size in relation to the mean proportion of calves in the national-level harvest. Horizontal error bars show $\pm 1 \mathrm{SE}$ of the mean

and West Grampian, the number of adult females in the harvest had a significant negative effect on $\mathrm{Hr}$ in the current year only $\left(\right.$ Scotland $_{t}-0.271 ; 95 \%$ CI -0.524 , $-0.019)$.

By contrast, and in support of our first prediction, the number of calves in the harvest had no influence on $\mathrm{Hr}$ in either the current or the following year at the national level $\left(H r_{t}-0.012 ; 95 \%\right.$ CI $-0.024,0.001$; generalised $R^{2}=0.006$; $H r_{t^{+}}-0.008 ; 95 \%$ CI $-0.020,0.004$, generalised $R^{2}=$ 0.001; Fig. 2). Similarly, within the regional harvests, the number of calves in the harvest had no significant effect on $\mathrm{Hr}$ in either the current or the following year in any case except for a significant negative effect in the Norwegian region of Sogn and Fjordane in the current year Norway $_{t}-0.086$; 95\% CI $-0.166,-0.007$; Fig. 3). Overall, therefore, any effect on the harvest growth rate was much weaker when harvesting juveniles than adult females.

The effect of harvest composition on the variance in harvest size

There was a non-significant negative correlation between coefficient of variation in $\log _{n}$ harvest size and the proportion of calves in the harvest at the national level (Fig. 4). Our detrended measure of national harvest size showed significant heteroscedasticity between countries (Bartlett's $K^{2}=36.89, \mathrm{df}=6, P<0.001$ ), but we found no evidence to suggest this increased with a decrease in the proportion of calves in the harvest. Modelling the variance in detrended harvest size as a function of the proportion of calves in the harvest (model 5, Table 2 "National harvests") gave a model with a similar AICc to the model that did not account for heteroscedasticity at all (model 4, Table 2 "National harvests"). Neither of these models received any statistical support (Akaike weight $<0.05$, Table 2 "National harvests"). Instead, much of the heteroscedasticity was explained by fitting different variances for each country (model 1, Table 2 "National harvests"). This model had the lowest AICc and the highest Akaike weight (0.697), indicating that variance in the structure of the harvest

Table 2 The effect of fitting different variance structures to model heterogeneity in the detrended harvest size $(h)$ at the national level and the regional level using GLS models

\begin{tabular}{|c|c|c|c|c|c|c|}
\hline Model & Variance structure & $\operatorname{Var}\left(\varepsilon_{i j}\right)$ & $k$ values & $\mathrm{AICc}$ & $\triangle \mathrm{AICc}$ & $w$ values \\
\hline \multicolumn{7}{|c|}{ National harvests, generalised $R^{2}=0.152$} \\
\hline 1 & Different variance among countries & $\sigma_{j}^{2}$ & 23 & -285.2 & 0.00 & 0.697 \\
\hline 2 & Different variance among countries and heteroscedastic effect of prop. calves & $\sigma_{j}^{2} \times e^{2 \delta \times c} i j$ & 24 & -283.5 & 1.69 & 0.300 \\
\hline 3 & Heteroscedastic effect of prop. calves differs between countries & $\sigma_{j}^{2} \times e^{2 \delta} j^{\times c} i$ & 24 & -274.3 & 10.9 & 0.003 \\
\hline 4 & Homoscedastic & $\sigma^{2}$ & 17 & -267.5 & 17.7 & 0.000 \\
\hline 5 & Heteroscedastic effect of prop. calves & $\sigma_{j}^{2} \times e^{2 \delta \times c} i$ & 18 & -265.7 & 19.5 & 0.000 \\
\hline \multicolumn{7}{|c|}{ Regional harvests, generalised $R^{2}=0.118$} \\
\hline 1 & Different variance among countries & $\sigma_{j}^{2}$ & 14 & -126.5 & 0.000 & 0.537 \\
\hline 2 & Different variance among countries and heteroscedastic effect of prop. calves & $\sigma_{j}^{2} \times e^{2 \delta \times c} i j$ & 15 & -126.2 & 0.358 & 0.449 \\
\hline 3 & Heteroscedastic effect of prop. calves & $\sigma^{2} \times e^{2 \delta \times c} i$ & 12 & -118.0 & 8.512 & 0.008 \\
\hline 4 & Homoscedastic & $\sigma^{2}$ & 11 & -117.8 & 8.760 & 0.007 \\
\hline 5 & Heteroscedastic effect of prop. calves differs between countries & $\sigma^{2} \times e^{2 \delta} j^{\times c} i$ & 15 & -112.2 & 14.28 & 0.000 \\
\hline
\end{tabular}

Model structure for the fixed effects is: $h_{i j} \sim c_{i j} * \operatorname{country}_{j}+c_{i} *$ year $+\varepsilon_{i j}$ where $c$ is the detrended proportion of calves in the harvest, $\varepsilon_{i j}$ is the error for the $i$ th observation in country $j$ and $*$ denotes a main effect+interaction. Heteroscedasticity in the error term $\varepsilon_{i j}$ was modelled with different combinations of country [factor with seven levels for national harvests, four levels for regional harvests) and detrended proportion of calves in the harvest $(c)]$ 
composition differed between countries. The only competing model also had different variances for each country but, in addition, allowed for a change in residual spread with an increase in the proportion of calves in the harvest (model 2, weight $=0.300$; Table 2 "National harvests"). However, contrary to expectation, the parameter estimate for this was positive, though not significant $(2.710,95 \%$ CI -3.417 , 8.837), suggesting no decrease in the variability of harvest size with more calves in the harvest.

At the regional level, there was also significant heteroscedasticity in the detrended harvest size (Bartlett's $K^{2}=$ 19.46, $\mathrm{df}=3, P<0.001)$. At this scale, country again contributed most to the observed heterogeneity. The two models with substantial statistical support had different variances between countries (models 1 and 2, Table 2 "Regional harvests"). As at the national scale, the secondbest model also included a heteroscedastic effect of the proportion of calves on the variance of harvest size. In this case, it competed strongly with the best model which had a variance structure of country alone (Akaike weights of 0.449 and 0.537 , respectively). However, as at the national scale, the parameter estimate of the proportion of calves on the harvest size variance was positive $(5.413,95 \%$ CI $-1.944,12.771)$, suggesting, contrary to expectation, no decrease in variance with increasing proportion of calves in the harvest. Overall, we found little support for a substantial effect of the proportion of calves in the harvest on the temporal variability of the harvest growth rate.

\section{Discussion}

Harvesting of juvenile ungulate game species has become an increasingly common management practise in Europe since the 1970s (Milner et al. 2006). However, many hunters continue to be reluctant to do this (Sæther et al. 2009; Festa-Bianchet 2007) and find the reasoning unclear. We show that, while there are many theoretical and verbal arguments for harvesting juveniles, there is relatively little empirical evidence of its effects (Table 1).

Despite being based on coarse-scale data, our comparison of harvest statistics of Red Deer from seven European countries provides empirical evidence that harvesting juveniles has little effect on harvest growth rate while harvesting adult females has a significant negative effect $\left(\mathrm{P}_{1}\right)$. Another, though less well-developed, demographic argument for the implementation of a juvenile harvesting regime is that reduced variance should result (Table 1). We found no empirical evidence that increasing the proportion of juveniles in the harvest decreases the variability in harvest between years $\left(\mathrm{P}_{2}\right)$. Though the argument for reduced variance is valid theoretically [juveniles have lower and more variable natural survival (Gaillard et al. 1998)], it is either not an important determinant of variance in harvest growth rates or harvesting rates were too low for an effect to be detectable. The former may partly be due to a counter-effect, whereby hunting juveniles exaggerates year-to-year fluctuations in juvenile survival because the pre-hunt juvenile population can vary considerably between years while the juvenile hunting quota is relatively constant between years (Ericsson 1999). Furthermore, because hunting quotas tend to be relatively constant between years, harvest growth rate is likely to be less sensitive to interannual variations in population abundance than population growth rate. Moreover, low hunting pressure on calves is unlikely to cause a sufficient decrease in variance in population growth rate to be detectable with the coarse data available. Calf harvesting rates were zero or very low during the first half of the study period in the non-Central European countries (Milner et al. 2006). Towards the end of the study, they were thought to be in the range of $10-25 \%$ of calves in the pre-hunt population, being highest in Central Europe.

Selective harvesting of juveniles - a strategy for low-density situations?

Selective harvesting regimes focusing on the removal of individuals with low reproductive value, such as the "antlered hunt" in North America and juvenile harvesting schemes in Scandinavia, were developed during periods with low population densities of large herbivores. These harvesting regimes aimed to increase population growth, as would be expected from theoretical modelling (Table 1). Simulation models of moose show that such a harvesting strategy can increase population size (Sæther et al. 1992) and population growth rate (Ericsson et al. 2000). This is supported by empirical evidence of a harvested moose population (Solberg et al. 1999). In our study, harvesting juveniles had no significant or a weak negative effect on harvest growth rate, partly because adult females continued to be harvested simultaneously to the calf harvest. It is also possible that the difference in the magnitude of the responses between Red Deer and moose arises from the unusually high reproductive output of moose (higher twinning rates and earlier age of first reproduction than expected for their body size; Gaillard 2007) compared with Red Deer. Other highly productive species such as Roe Deer (Capreolus capreolus) and wild boar (Sus scrofa) may also be expected to show a positive growth response to harvesting juveniles.

Currently, similar harvesting strategies tend to be applied across ungulate game species, although strategies may differ between countries or regions depending on hunting cultures (Milner et al. 2006). However, this may not be the optimal way to manage ungulates (Festa-Bianchet 2007), especially if harvest responses differ between species. As 
over-abundance of ungulates becomes an increasing problem in the northern hemisphere (Côté et al. 2004; McShea et al. 1997), a harvesting strategy that promotes population productivity is now less appropriate in many regions. Consequently, harvesting juveniles alone should not be recommended under these circumstances. Instead, our study shows that harvesting adult females reduces harvest growth rate indicating that this is a more suitable harvesting regime in areas with over-abundance issues, at least from a demographic perspective.

\section{Harvesting juveniles vs. yearlings}

A common argument among hunters is that it is better to shoot yearlings rather than calves. However, in most ungulate species, yearling survival rates are high and reproductive values are much greater than in juveniles so many of the advantages of juvenile harvesting would be lost, although meat yield would be better (Nilsen et al. 2005; Sylven 1995). For example, if the management goal is to increase the harvest size while minimising the impact on population growth, then harvesting juveniles would be better than yearlings because of the higher reproductive value of yearlings.

In agricultural systems, juveniles are routinely harvested despite relatively low body weights compared with mature animals because they are the age group with the fastest growth rate, they either compete for resources with breeding stock or require costly inputs to maintain them over winter, or young animals attract higher meat prices (Skonhoft et al. 2010). However, applying a livestock production model to wildlife is problematic. In livestock production, it is typically only the male juveniles which are cropped, while most females are kept for breeding stock replacement. Under hunting conditions, selective harvesting of only male juveniles cannot be achieved due to the difficulty in distinguishing between males and females at this age, suggesting that practical management arguments also form a central role on this issue. If half of the juveniles shot are females, the future stock of reproductive animals is reduced, imposing an upper limit to the proportion of juveniles that can be sustainably exploited. If instead yearlings are harvested, differentiation between the sexes is possible. Furthermore, while young of the year are cropped in relatively small-bodied livestock such as sheep, goats and semi-domesticated reindeer, cattle are more typically cropped at one and a half years of age. Similarly, it may be more appropriate to harvest large game animals such as moose as yearlings rather than calves, although this is dependent on hunters being able to distinguish yearlings from adults.

Our understanding of the relative advantages and disadvantages of harvesting juveniles versus yearlings is hampered by the fact that most modelling studies group yearlings with adults despite differences in growth rates, body size and reproductive value (but see Sylven et al. 1987; Sæther et al. 1992). In many cases, hunting statistics are also reported by grouping yearlings and adults. The relative benefits of harvesting juveniles compared with yearlings are likely to differ between species, but have not been studied. A cross-species study is therefore required where life history traits, such as body size, litter size and age- and sex-specific survival rates, are included so that it can be established whether there are circumstances or species in which it is optimal to harvest yearlings rather than juveniles. This may be an additional reason for not applying uniform harvesting regimes across species.

\section{Conclusions}

Our results show that the rationale for harvesting juvenile ungulates is weakly supported by demographic arguments. In particular, empirical evidence from Red Deer harvesting in seven European countries suggest this strategy is unlikely to reduce variance in the harvest, at least with the harvest rates observed in our study. An increasing number of studies are showing detrimental evolutionary and demographic effects of size selective harvesting which focuses on large adults (see reviews by Fenberg and Roy 2008; Festa-Bianchet 2003; Harris et al. 2002; Milner et al. 2007; Mysterud et al. 2002a). In particular, a high harvest rate of adults relative to juveniles leads to selection for reduced body size (Coltman et al. 2003; Proaktor et al. 2007) and early reproduction (Proaktor et al. 2007; Mysterud et al. 2009). The former is not compatible with sustainable management of trophy hunting while the latter is likely to exacerbate problems of over-abundant ungulates. Harvesting juveniles, which more closely mimics natural mortality patterns (Ginsberg and Milner-Gulland 1994; Festa-Bianchet 2007), may limit these detrimental effects under certain circumstances (Bischof et al. 2008). Having a high juvenile harvest may indeed be good based on evolutionary arguments (Proaktor et al. 2007). We therefore urge managers to consider not only demographic arguments, but also to consider the evolutionary and practical management ones (Table 1). A limitation of our study is the absence of good harvest rate data. We therefore see a strong need for more empirical work, particularly on marked individuals in hunted populations, to enable the optimal management of our large herbivore resource.

Acknowledgements We thank all the agencies who kindly provided harvest statistics data and Sándor Csányi, Mike Daniels, François Klein, Bostjan Pokorny and Karoline Schmidt for help locating data and providing additional information. Financial support was from the Norwegian Research Council (NFR 156367/530). 
Open Access This article is distributed under the terms of the Creative Commons Attribution Noncommercial License which permits any noncommercial use, distribution, and reproduction in any medium, provided the original author(s) and source are credited.

\section{References}

Ahlén I (1975) Winter habitats of moose and deer in relation to land use in Scandinavia. Swed Wildlife Res 9:45-192

Aitchison J (1986) The statistical analysis of compositional data. Chapman and Hall, London, England; pp 416

Bischof R, Mysterud A, Swenson JE (2008) Should hunting mortality mimic the patterns of natural mortality? Biol Lett 4:307-310

Caughley G (1977) Analysis of vertebrate populations. Wiley, Chichester

Coltman DW, O’Donoghue P, Jorgensen JT, Hogg JT, Strobeck C, Festa-Bianchet M (2003) Undesirable evolutionary consequences of trophy hunting. Nature 426:655-658

Côté SD, Rooney TP, Tremblay J-P, Dussault C, Waller DM (2004) Ecological impacts of deer overabundance. Ann Rev Ecol Syst 35:113-147

Dray S, Dufour AB (2007) The ade4 package: implementing the duality diagram for ecologists. J Stat Softw 22:1-20

Ericsson G (1999) Demographic and life history consequences of harvest in a Swedish moose population. Swedish University of Agricultural Sciences, Umeå

Ericsson G, Boman M, Mattsson L (2000) Selective versus random moose harvesting: does it pay to be a prudent predator? J Bioecon 2:117-132

Fenberg PB, Roy K (2008) Ecological and evolutionary consequences of size-selective harvesting: how much do we know? Mol Ecol 17:209-220

Festa-Bianchet M (2003) Exploitative wildlife management as a selective pressure for life-history evolution of large mammals. In: Festa-Bianchet M, Apollonio M (eds) Animal behavior and wildlife conservation. Island Press, Washington DC, pp 191210

Festa-Bianchet M (2007) Ecology, evolution, economics and ungulate management. In: Hewitt DG, Fulbright TE (eds) Wildlife science: linking ecological theory and management applications. CRC Press, Boca Raton, FL, pp 183-202

Gaillard J-M, Festa-Bianchet M, Yoccoz NG (1998) Population dynamics of large herbivores: variable recruitment with constant adult survival. Trends Ecol Evol 13:58-63

Gaillard J-M, Festa-Bianchet M, Yoccoz NG, Loison A, Toïgo C (2000) Temporal variation in fitness components and population dynamics of large herbivores. Ann Rev Ecol Syst 31:367-393

Gaillard J-M, Loison A, Toïgo C (2003) Variation in life history traits and realistic population models for wildlife management: the case of ungulates. In: Festa-Bianchet M, Apollonio M (eds) Animal behavior and wildlife conservation. Island Press, Washington D. C, pp 115-132

Gaillard J-M (2007) Are moose only a large deer?: some life history considerations. Alces 43:1-11

Ginsberg JR, Milner-Gulland EJ (1994) Sex-biased harvesting and population dynamics in ungulates: implications for conservation and sustainable use. Conserv Biol 8(1):157-166

Gordon IJ, Hester AJ, Festa-Bianchet M (2004) The management of wild large herbivores to meet economic, conservation and environmental objectives. J Appl Ecol 41:1021-1031

Grosbois V, Gimenez O, Gaillard J-M, Pradel R, Barbraud C, Clobert J, Møller AP, Weimerskirch H (2008) Assessing the impact of climate variation on survival in vertebrate populations. Biol Rev 83:357-399
Haagenrud H, Lørdahl L (1974) Rettet avskyting i elgbestander. (In Norwegian) preliminary report No. 3. Agricultural University, Ås

Harris RB, Wall WA, Allendorf FW (2002) Genetic consequences of hunting: what do we know and what should we do? Wildl Soc Bull 30:634-643

Hjeljord O (1981) Moose-winter forage and selective harvesting (In Norwegian). Nor Skogbruk 10:11-13

Kojola I, Helle T (1993) Calf harvest and reproductive rate of reindeer in Finland. J Wildl Manage 57:451-453

Kokko H (2001) Optimal and suboptimal use of compensatory responses to harvesting: timing of hunting as an example. Wildl Biol 7:141-150

Langvatn R, Loison A (1999) Consequences of harvesting on age structure, sex ratio and population dynamics of Red Deer Cervus elaphus in central Norway. Wildl Biol 5:213-223

Legendre P, Legendre L (1998) Numerical ecology, 2nd edn, Elsevier Science, Amsterdam, The Netherlands

McCullough DR (1996) Spatially structured populations and harvest theory. J Wildl Manage 60:1-9

McCullough DR (2001) Male harvest in relation to female removals in a black-tailed deer population. J Wildl Manage 65:46-58

McShea WJ, Underwood HB, Rappole JH (eds) (1997) The science of overabundance. Deer ecology and population management. Smithsonian Institute Press Washington, DC

Milner JM, Bonenfant C, Mysterud A, Gaillard J-M, Csányi S, Stenseth NC (2006) Temporal and spatial development of red deer harvesting in Europe: biological and cultural factors. J Appl Ecol 43:721-734

Milner JM, Nilsen EB, Andreassen HP (2007) Demographic side effects of selective hunting in ungulates and carnivores. Conserv Biol 21:36-47

Mitschke G (1960) Entwicklung des deutschen jagdrechts bis zum reichsjagdgesetz. In: Jagdschutzverband D (ed) Ulrich scherping und ein halbes jahrhundert deutscher jagdgeschichte. Parey, Berlin, pp 32-37

Moe T, Solberg EJ, Herfindal I, Sæther B-E, Bjørneraas K, Heim M (2008) Sex ratio variation in harvested moose (Alces alces) calves: does it reflect population calf sex ratio or selective hunting? Eur J Wildl Res 55:217-226

Mysterud A, Coulson T, Stenseth NC (2002a) The role of males in the dynamics of ungulate populations. J Anim Ecol 71:907-915

Mysterud A, Langvatn R, Yoccoz NG, Stenseth NC (2002b) Largescale habitat variability, delayed density effects and Red Deer population in Norway. J Anim Ecol 71:569-580

Mysterud A, Stenseth NC, Yoccoz NG, Ottersen G, Langvatn R (2003) The response of the terrestrial ecosystems to climate variability associated with the North Ntlantic oscillation. In: Hurrell JW, Belgrano A, Ottersen G, Kushnir Y (eds) The North Atlantic oscillations. Climatic significance and environmental impact. American Geophysical Union, pp 235-262

Mysterud A, Yoccoz NG, Langvatn R (2009) Maturation trends in red deer females over 39 years in harvested populations. J Anim Ecol 78:595-599. doi:10.1111/j.1365-2656.2008.01514.x

Nilsen EB, Pettersen T, Gundersen H, Milner JM, Mysterud A, Solberg EJ, Andreassen HP, Stenseth NC (2005) Moose harvesting strategies in the presence of wolves. J Appl Ecol 42:389-399

Østgård J (1987) Status of moose in Norway in the 1970's and early 1980's. Swed Wildlife Res Suppl 1:63-68

Pinheiro JC, Bates DM (2000) Mixed-effects models in s and s-plus. Statistics and computing. Springer-Verlag, New York

Proaktor G, Coulson T, Milner-Gulland EJ (2007) Evolutionary responses to harvesting in ungulates. J Anim Ecol 76:669678

R Development Core Team (2007) R: a language and environment for statistical computing., version 2.5.1 edn. R Foundation for Statistical Computing Vienna, Austria 
Sæther BE, Solbraa K, Sødal DP, Hjeljord O (1992) Sluttrapport elgskog-samfunn (In Norwegian), vol 28

Sæther B-E, Engen S, Solberg EJ (2001) Optimal harvest of agestructured populations of moose Alces alces in a fluctuating environment. Wildl Biol 7(3):171-179

Sæther B-E, Engen S, Solberg EJ, Heim M (2007) Estimating the growth of a newly established moose population using reproductive value. Ecography 30:417-421. doi:10.1111/j.2007.09067590.05006.x

Sæther BE, Engen S, Solberg EJ (2009) Effective size of harvested ungulate populations. Anim Conserv 12:488-495

Servanty S, Gaillard J-M, Toïgo C, Brandt S, Baubet E (2009) Pulsed resources and climate-induced variation in the reproductive traits of wild boar under high hunting pressure. J Anim Ecol 78:12781290

Skonhoft A, Austrheim G, Mysterud A (2010) A bioeconomic sheepvegetation trade-off model. An analysis of the Nordic sheep farming system. Nat Resour Modelling 23:354-380
Solberg EJ, Sæther B-E, Strand O, Loison A (1999) Dynamics of a harvested moose population in a variable environment. J Anim Ecol 68:186-204

Stearns SC (1992) The evolution of life histories. Oxford University Press, Oxford

Sutherland WJ (2001) Sustainable exploitation: a review of principles and methods. Wildl Biol 7:131-140

Sylven S (1995) Moose harvest strategy to maximize yield value for multiple goal management - a simulation study. Agric Syst 49:277-298

Sylven S, Cederlund G, Haagenrud H (1987) Theoretical considerations on regulated harvest of a moose population - a simulation study. Swed Wildl Res Suppl 1:643-656

Widemo F (2010) Hunters and moose management (In Swedish). Sven Jakt 148:78-82

Zheng B, Agresti A (2000) Summarizing the predictive power of a generalized linear model. Stat Med 19:1771-1781

Zuur AF, Ieno EN, Walker NJ, Saveliev AA, Smith GM (2009) Mixed effects models and extensions in ecology with R. Springer, New York 